\title{
Violência Contra Idosos na Família: Motivações, Sentimentos e Necessidades do Agressor
}

\author{
Cirlene Francisca Sales Silva \\ Universidade Católica de Pernambuco, Recife, \\ PE, Brasil.
}

\author{
Cristina Maria de Souza Brito Dias \\ Universidade Católica de Pernambuco, Recife, \\ PE, Brasil.
}

\begin{abstract}
Resumo: O aumento mundial da população idosa tem sido acompanhado por importantes demandas, dentre elas a violência contra a pessoa idosa, que merece especial atenção devido às sequelas físicas e psicológicas que acarreta. A literatura tem focalizado mais o idoso agredido, pouco se detendo ao agressor. $\mathrm{O}$ objetivo geral desta pesquisa foi investigar a violência contra idosos na família, da perspectiva do agressor, especificamente as motivações que os impeliram à violência, os sentimentos e as necessidades sentidas por eles. Pesquisa descritiva de abordagem qualitativa, tendo dela participado 13 agressores familiares dos idosos. Utilizou-se um roteiro de entrevista semiestruturada que foi examinado por meio da Análise de Conteúdo Temática. Os resultados indicam que houve a presença de violência com agressões verbais e físicas; as principais motivações foram uso de álcool, proximidade física, dependência financeira do agressor em relação ao idoso e relacionamento permeado de violência entre ambos; os sentimentos experimentados foram tristeza, decepção, raiva, injustiça, angústia e revolta; as necessidades se relacionam ao desejo de que o processo fosse encerrado, voltar à sua vida normal e conviver com o idoso. Conclui-se acerca da necessidade de acolhimento aos agressores com a finalidade de ajudá-los a ressignificar a experiência da violência.
\end{abstract}

Palavras-chave: Idoso, Violência, Família, Agressor.

\section{Violence Against the Elderly in the Family: Aggressor's Motivations, Feelings and Needs}

\begin{abstract}
The worldwide increase of elderly population has been accompanied by important demands, such as violence against this population. This deserves special attention because of the consequences that entails. The literature has focused more on the victim than on the offender. The overall objective of this study was to investigate the violence against the elderly in the family from the perspective of the aggressors, specifically their motivations, feelings and needs. 13 family aggressors of the elderly participated in this descriptive qualitative study. A semi-structured interview guide which was analyzed through Thematic Content Analysis was used. The results indicate that: there was violence through verbal and physical aggression; the main motivations were alcohol use, physical proximity, financial dependence of the abuser in relation to the elderly, being the main motivation a relationship permeated with violence. The feelings experienced by aggressors were sadness, disappointment, anger, injustice, grief and the desire that the cycle was closed so they could return to their normal life. It was concluded that it is necessary to embrace the aggressors in order to help them reframe this experience.
\end{abstract}

Keywords: Elderly, Violence, Family, Aggressor. 


\title{
La Violencia Contra las Personas Mayores en la Familia: Motivaciones, Sentimientos y Necesidades De Los Agresores
}

\begin{abstract}
Resumen: El aumento mundial de la población anciana ha sido acompañado de demandas importantes, entre ellas, la violencia contra las personas de edad avanzada, lo que merece una atención especial, debido a las consecuencias físicas y psicológicas que conlleva. La literatura se ha centrado con mucha más intensidad en el anciano agredido, deteniéndose poco en el delincuente. El objetivo general de esta investigación fue estudiar la violencia contra las personas mayores en la familia, desde la perspectiva de los agresores, específicamente las motivaciones que produjeron la violencia, los sentimientos y las necesidades sentidas por estos agresores. Esta es una investigación descriptiva con enfoque cualitativo. 13 personas fueron encuestadas, todas agresores y parientes de ancianos. Se desarrolló y se utilizó una guía de encuesta semiestructurada que fue analizada a partir del Análisis de Contenido Temático. Los resultados prevalecientes indican que hubo presencia de violencia verbal y agresiones físicas. Las principales motivaciones fueron: el consumo de bebidas alcohólicas, la proximidad física, la dependencia económica del agresor frente al anciano y la relación impregnada de violencia entre ellos; los sentimientos cargados de tristeza, decepción, ira, injusticia, melancolía y molestia; las necesidades estuvieron relacionadas con el deseo de que el proceso de cuidar al anciano acabase para retomar rutinas habituales. Llegamos a la conclusión de que es necesario acoger a los agresores con el fin de ayudarles a replantear la experiencia
\end{abstract}

Palabras clave: Anciano, Violencia, Familia, Agresor.

\section{Introdução}

Violência, agressão, maus-tratos, abusos contra os idosos são expressões que dizem respeito a processos e a relações sociais interpessoais, de grupos, de classes, de gênero, ou ainda institucionais, que causem danos físicos, danos psicológicos e morais à pessoa. Neste trabalho, entende-se "violência" como "agressões", "abusos" e "maus tratos", pois referenciam o sentido de dano causado à pessoa idosa (Minayo, 2008; Muchembled, 2012). Segundo o Dicionário "online" de Português (Agressor, 2015), por agressor define-se aquele (a) que ataca, agride e é provocador. Enquanto abusador a pessoa que abusa, faz "pouco caso", ridiculariza o outro.

A violência contra os idosos é uma importante demanda que tem acompanhado o crescimento dessa população, acarretando adoecimento físico (doenças psicossomáticas, diminuição gradual de suas defesas físicas, alterações do sono e apetite, desidratação, desnutrição, entre outros) e adoecimento psicológico (depressão, desordem pós-traumática, agitação, fadiga, perda de identidade, tentativas de suicídio), quando não culminando com a morte (Barcelos, \& Madureira, 2013; Gondim, \& Costa, 2006). Segundo
Gaioli e Rodrigues (2008), os maus-tratos aos idosos estão cada vez mais evidentes na sociedade, adquirindo dimensão social e de saúde pública.

Trata-se de um problema universal que acontece em diferentes culturas, independentemente de status socioeconômico, etnia e religião. Conforme Leite, Hildebrandt e Santos (2008), as questões culturais também podem contribuir para que haja violência, em especial no ambiente doméstico no qual o idoso, não raro, é desvalorizado, visto como uma pessoa inútil e relegado à marginalização. Nacional e internacionalmente, há algumas categorias e tipologias padronizadas para designar as formas mais frequentes de violência praticadas contra a população idosa. A classificação e a conceituação aqui descritas estão oficializadas no documento denominado "Política Nacional de Redução de Acidentes e Violências", aprovado como Portaria do Ministério da Saúde, no dia 16 de maio de 2001 (Brasil, 2005). São elas: abuso físico, maus-tratos físicos ou violência física; abuso psicológico, violência psicológica ou maus-tratos psicológicos, traduzidos pelas agressões verbais; abuso sexual ou violência sexual; abandono; negligência; abuso financeiro ou econômico; autonegligência. Além das que 
foram citadas, incluem-se também: a discriminação; a exclusão do idoso do mercado de trabalho ou a exploração de sua mão de obra; a poluição sonora; a violência medicamentosa, consistindo no uso inapropriado ou excessivo de remédios não prescritos.

Conforme Pasinato, Camarano e Machado (2006), a violência contra idosos é um fenômeno de notificação recente no mundo e no Brasil. Pela primeira vez, em 1975, os abusos contra idosos foram descritos em revistas científicas britânicas como espancamento de avós. Minayo (2005) refere que, no Brasil, a questão começou a ganhar notoriedade a partir de 1990, bem depois que a preocupação com a qualidade de vida dos idosos entrou na agenda da saúde pública brasileira. Embora já exista uma crescente bibliografia acerca do tema, com importantes autores que pesquisam e escrevem sobre o assunto, tais como Faleiros que realizou uma pesquisa nacional sobre o tema, publicada em livro (2007), Faleiros (2013), Faleiros e Brito (2009), Minayo (2005, 2008, 2010), entre outros, são escassos os artigos focalizando especificamente a figura do agressor de idosos na família. Foram realizadas buscas nas Bases de dados da Biblioteca Virtual em Saúde - BVS/BIREME que abrangem a LILACS, IBECS, MEDLINE, Biblioteca Cochrane, SciELO; Science Direct; Capes - Periódicos; Psicodoc; Pubmed, livros, dissertações e teses, e não foram encontradas pesquisas que, de fato, investigassem os agressores de forma mais específica.

O objetivo geral desta pesquisa foi investigar a violência contra idosos na família, da perspectiva do agressor. Especificamente, foram analisados: a presença e os tipos de violência; as motivações que impeliram à prática da violência; os sentimentos experimentados na situação atual e as necessidades sentidas por eles. Espera-se dar visibilidade a esse personagem para que se possa entender melhor o contexto que gerou a violência e contribuir para que os agressores possam ressignificar essa experiência através do acolhimento e de uma escuta sensível.

Segundo a Teoria dos Sistemas (Bertalanffy, 2008), as propriedades essenciais de um organismo ou sistema vivo são propriedades do todo. Elas surgem das interações e relações entre as partes. Essas propriedades são destruídas quando o sistema é reduzido a elementos isolados. O todo é sempre maior que a soma de suas partes. Assim, não faria muito sentido tentar entender o comportamento do agressor apenas focando sua figura sem observar o restante da família e o contexto onde se dá a relação. É importante também verificar se essa relação construída ao longo do tempo produz agredidos e agressores, uma vez que ambos se afetam circularmente.

Bertalanffy (2008) afirma que a família é um sistema aberto que permuta matéria, energia ou informação com o meio. É orientado para a vida e o crescimento. A família, enquanto sistema aberto, interage com outros sistemas sociais (escola, igreja, comunidade) e seus subsistemas (elementos que compõem o sistema). Desse modo, ela pode oferecer um ambiente saudável para o idoso ou, pelo contrário, deixar-se contaminar pela violência que caracteriza nossa sociedade, o macrossistema, e reproduzi-la em suas relações. As violências interpessoal, intrafamiliar ou doméstica ocorrem entre membros da família ou parceiros íntimos. As relações tensas desenvolvidas no espaço familiar, somadas ao imaginário social de que a velhice é acompanhada de desprezo e inutilidade, geram o ambiente propício para que se estabeleçam interações conflituosas e violentas, seja entre os casais idosos, entre os filhos e idosos ou mesmo entre cuidadores e idosos.

Yan, Chan e Tiwari (2014) realizaram uma revisão sistemática da prevalência e fatores de risco para o abuso em idosos. Eles afirmaram que o abuso é prevalente em todo o mundo e que estudos prospectivos sugerem que pessoas mais velhas sujeitadas ao abuso e negligência têm um risco de mortalidade maior do que aqueles que não são vítimas. Nos Estados Unidos, 5 a $10 \%$ de pessoas com 65 anos ou mais de idade foram abusadas por alguém de quem dependem para o cuidado ou proteção. No Canadá, as taxas de prevalência são de $7 \%$ para a violência emocional, $1 \%$ para as questões financeiras bem como abuso físico ou sexual, enquanto que, no Reino Unido, são de 5,4\% para a violência emocional ou verbal, $1,5 \%$ para física e $1,5 \%$ para abuso financeiro. Segundo os autores, é esperado um aumento no número de pessoas idosas vítimas de abuso, dado que muitos países estão atravessando um rápido envelhecimento da população. Isso é particularmente agudo na Ásia cuja população passa por um ritmo de envelhecimento sem precedentes. Em 2012, 11\% dos asiáticos possuíam 60 anos ou mais, um número que deverá subir para $24 \%$ até 2050 . Eles apontam ainda que o maior aumento no envelhecimento da população, 
deverá ocorrer nos próximos 75 anos, chegando a $27 \%$ em 2050, o que, consequentemente, poderá contribuir para o aumento da violência.

Pesquisas realizadas em várias partes do mundo revelam que cerca de 2/3 dos agressores são filhos e cônjuges (Minayo, 2005; 2008). O perfil do abusador de idosos revela que predominam os filhos homens ou, em algumas situações, as filhas mulheres, seguidos das noras e dos genros e, em terceiro lugar, o cônjuge. A caracterização do agressor aponta o predomínio de algumas circunstâncias: (1) ele vive na mesma casa que a vítima; (2) é um filho(a) dependente financeiramente de seus pais de idade avançada, ou o idoso depende dele; (3) é um familiar que responde pela manutenção do idoso sem renda própria e suficiente; (4) é um abusador de álcool ou drogas ou alguém que pune o idoso usuário dessas substâncias; (5) é alguém que se vinga do idoso que com ele mantinha vínculos afetivos frouxos, que abandonou a família ou foi muito agressivo e violento no passado; (6) é um cuidador com problema de isolamento social ou de transtornos mentais; (7) o fato de haver história de violência na família; (8) o agressor ter sofrido, ou ainda sofrer, agressões por parte do idoso, o que o leva, por vezes, a descarregar no idoso sentimentos de ambivalência, inadequação, inferioridade e cansaço (Minayo, 2005; 2008; Minayo, Souza, \& Paula, 2010).

Quando a pessoa que cuida ou mora com o idoso apresenta problemas com dependência de drogas, destacando-se o álcool, ou dificuldades emocionais, aumenta o risco de maus-tratos. Grossi e Souza (2003) constataram que mais de $50 \%$ dos idosos cujos familiares são usuários de álcool/drogas sofrem algum tipo de abuso físico ou emocional. Somando-se aos estudos citados, Papalia, Olds e Feldman (2006) pontuaram que muitos idosos vivem com os filhos adultos e que o êxito desse esquema depende principalmente da qualidade do relacionamento que existiu no passado e da capacidade de ambas as gerações se comunicarem de maneira plena e honesta.

No que concerne à especificidade de gênero, as investigações sobre a violência contra a pessoa idosa (Faleiros, \& Brito, 2009; Papalia et al., 2006) mostraram que, no interior da casa, as mulheres são mais abusadas que os homens. São agredidas principalmente as que são solteiras e que não têm sua casa ou renda própria, precisando, portanto, morar com familiares.
Além desses, existem vários estudos nacionais e internacionais de autores como Abath, Leal e Melo Filho (2012); Faleiros, (2013); Lourenço, Mota, Carvalho, Gebara e Ronzani (2012); Minayo et al. (2010); Nogueira, Freitas e Almeida (2011); Pinto, Barham e Albuquerque (2013); Silva, Coelho e Moretti-Pires (2014); Sousa et al. (2010), realizados nos últimos cinco anos, que tratam da temática da violência contra pessoa idosa e que apresentam importantes contribuições para a compreensão da questão. Todavia, no tocante ao acolhimento e escuta dos agressores familiares que não são cuidadores dos idosos, eles ainda são escassos. Neste estudo, serão focalizadas pesquisas realizadas no estado de Pernambuco, por ser o local da realização da presente investigação, como também em outros estados brasileiros, para que a visão desse fenômeno possa ser ampliada.

Algumas características biopsicossociais foram unânimes nas pesquisas citadas: no que se refere ao agressor, predominou o sexo masculino; grau de parentesco, em primeiro lugar, filhos, seguidos de genros/noras e netos; idades entre 25 a 49 anos, independentemente de trabalharem ou não, embora prevaleçam os desempregados; faz uso de bebida alcoólica ou outras drogas; depende financeiramente ou emocionalmente do idoso; independente de religião; apresenta um histórico familiar de violência; reside com o idoso na mesma casa ou quintal. Quanto ao idoso agredido: trata-se de pessoa com idade acima dos 70 anos, do sexo feminino (com exceção de resultado encontrado por Minayo et al. (2010), que aponta os homens como mais agredidos); viúvo(a) ou solteiro(a); aposentado(a); com baixa escolaridade e que depende física, emocional ou financeiramente do agressor com quem reside.

Minayo et al. (2010) realizaram uma revisão sistemática sobre a produção acadêmica brasileira de 2000 a 2009 a respeito das causas externas e das violências que vitimizam a população idosa. Os resultados apontaram um aumento da produção e aprimoramento metodológico em diversas áreas de atuação bem como na formulação de políticas e planos de ação. No entanto, ainda existem temas pouco aprofundados como acidentes de trânsito, homicídios, suicídios, afogamentos e sufocações. Elas encontraram três grandes pesquisas populacionais sobre a "violência doméstica ou intrafamiliar" que atinge a pessoa idosa, embora tenham apresentado poucas informações sobre os agressores. Elas acrescentam 
que: "Houve maior prevalência de abusos físicos graves nas residências com maior número de indivíduos e com histórias de enfermidades, sobretudo as articulares e diabete" (p. 2722).

Sousa et al. (2010) fizeram uma atualização ampla da literatura através da caracterização dos tipos de violência, do perfil do agressor e vítima, principais locais de ocorrência, indicadores, epidemiologia, instrumentos de detecção e propostas de resolução. Os autores afirmam que se depararam com:

A escassez de dados epidemiológicos atualizados que expressem a verdadeira dimensão estatística do problema, além da ausência de exploração científica minuciosa das diversas faces da violência contra o idoso. Observou-se, em algumas famílias, que o(a) idoso(a) demonstrava possuir uma personalidade dominadora e controladora, muitas vezes agredindo os filhos, o que pode ocasionar uma inversão nessas posições quando o pai ou a mãe envelhecem e se tornam dependentes deles. Outros aspectos seriam o estresse, além da exaustão física e emocional provenientes dos cuidados dispensados, principalmente em casos de o idoso depender de cuidados especiais de saúde (p. 321).

Nogueira et al. (2011) objetivaram conhecer os casos de violência e maus-tratos contra idosos no município de Fortaleza e destacaram que "os resultados apresentaram predomínio da violência intrafamiliar e a maior parte das denúncias foi anônima $(77,1 \%) "$ (p. 543). Lourenço et al. (2012) fizeram um estudo para focalizar a violência doméstica contra idosos na perspectiva das crenças dos profissionais da Atenção Primária à Saúde de Juiz de Fora. Os resultados apontaram que a atuação dos profissionais de saúde está restrita à prática de encaminhamentos. Afirmaram também que: os fatores apontados como determinantes para o aumento da ocorrência dos casos de violência doméstica foram as questões socioeconômicas $(50 \%)$; os valores sociais, como sensação de inutilidade e falta de solidariedade, amor, respeito e paciência (20\%); as dificuldades para lidar com o envelhecimento, como a ocorrência de doenças nessa idade e o tempo requerido para esses cuidados (15\%); o aumento da expectativa de vida (10\%); e outros, como a falta de conhecimento sobre o envelhecimento (7\%).
Pinto et al. (2013) realizaram um estudo que objetivou levantar qual o tipo mais comum de violência contra idosos, comparar o perfil dos idosos que sofreram violência doméstica com idosos da população geral e levantar quais foram seus principais agressores. Foram analisados 712 prontuários de um serviço de Disque-denúncia de uma cidade no interior de São Paulo. Os resultados apontam que a maioria dos casos envolvia negligência ou abandono. O perfil dos idosos vítimas de violência foi significativamente diferente da população geral de idosos em relação à sua escolaridade, estado civil e etnia, concluindo que os principais agressores são os filhos ou alguém da família, totalizando $92,5 \%$ dos casos denunciados. Os autores afirmam ainda que:

A cultura brasileira, apoiada pelo Estatuto do Idoso (Brasil, 2003), impõe como obrigação que a família seja responsável pelos cuidados dos membros idosos. Assim, é previsível que a negligência e o abandono sejam atribuídos a parentes. Na maioria das famílias com problemas de violência, os membros não possuem repertório interpessoal pró-social para lidar com dificuldades. Como consequência da ausência de habilidades de conviver com essas dificuldades ocorrem situações de negligência, abandono ou agressão física e psicológica. Essas situações possivelmente remetem esses familiares a sua história de contingências e ao modelo de conduta familiar desse idoso em suas interações, incluindo diferenças de expectativas e envolvimentos de cada geração, culminando em novos episódios de violência, que passam a ocorrer em ciclos (p. 1174).

Correia, Leal, Marques, Salgado e Melo (2012) realizaram um estudo que objetivou determinar o perfil da violência sofrida pelo idoso atendido em serviço de emergência do Hospital da Restauração (HR), em Recife, PE. Os resultados apontaram que o idoso vítima de violência foi principalmente do sexo masculino na faixa etária de $60-70$ anos. O tipo de violência mais frequente foi a física, especialmente contusão na face ou crânio, ocorrendo mais no fim de semana. Não houve menção de dados a respeito do agressor na maioria dos prontuários estudados $(97,3 \%)$ devido ao inadequado preenchimento dos prontuários. 
Abath et al. (2012) pesquisaram os fatores associados à violência doméstica do tipo física em idosos submetidos a exame de corpo de delito, entre $2004 \mathrm{e}$ 2007, no Instituto de Medicina Legal do Recife. Eles observaram que as partes do corpo mais susceptíveis à violência foram o tronco e os membros; que os fatores associados à violência estão vinculados a aspectos sociais, econômicos e culturais. Acrescentaram ainda que: a maioria dos agressores agiu só, ou seja, desacompanhado, o que parece demonstrar a fragilidade dos idosos, explicada por aspectos fisiológicos, psicológicos e socioeconômicos. Constataram relações enfraquecidas e história familiar prévia de violência que favoreceram o surgimento da agressão. Os autores concluem que:

As famílias despreparadas para compreender, administrar e tolerar seus próprios conflitos tendem a ser violentas. Independentemente de o agressor ser ou não um parente, a qualidade da relação entre ele e o idoso depende de crenças, valores e concepções sobre a velhice e o cuidado (p. 311).

\section{Método}

Trata-se de uma pesquisa descritiva com abordagem qualitativa.

\section{Participantes}

Para escolha dos participantes, foi feita análise documental dos processos que tinham os familiares como alvo de denúncia com a finalidade de selecionar os que tratavam de violência contra o idoso, nos Juizado Especial Criminal do Idoso e na I Vara de Violência Doméstica e Familiar contra a Mulher. Na primeira instituição, dos 110 processos que existiam com essa característica, 26 eram de violência praticada por familiares. Na segunda instituição, foram localizados 13 processos em tramitação totalizando, portanto, 39 processos. Todos os agressores foram convidados a participar da pesquisa, por meio de cartas registradas por correios e contato telefônico, tendo comparecido apenas 13. Os demais alegaram não poder participar por motivos vários. Constituíram-se como critério de inclusão para a pesquisa: os participantes terem praticado qualquer tipo de violência contra seu idoso; serem familiares, cuida- dores ou não, do idoso; ser maior de dezoito anos (independente do sexo, escolaridade, nível socioeconômico) e estar respondendo a processo judicial em andamento, aguardando a sentença final a ser prolatada pelo Juiz de Direito da Instituição judiciária. É importante destacar que nenhum dos agressores era seu cuidador, pois os(as) idosos(as) agredidos(as) não demandavam cuidados especiais.

\section{Instrumentos}

Questionário sociodemográfico contendo informações sobre o agressor como: sexo, idade, grau de escolaridade, estado civil, profissão, situação profissional, renda familiar, grau de parentesco com o idoso, se reside com o idoso, se depende financeiramente desse idoso, se é usuário de álcool ou outro tipo de drogas. E, através dos processos, foram coletadas as informações sobre o idoso agredido: sexo, idade, estado civil, situação profissional, grau de parentesco com o agressor e situação de proximidade física (se mora com o agressor na mesma casa ou quintal).

Roteiro de entrevista semiestruturada que combina perguntas fechadas e abertas, em que o entrevistado tem a possibilidade de discorrer sobre o tema em questão sem se prender à indagação formulada (Minayo, 2010). Foi composto por cinco perguntas elaboradas de acordo com os objetivos da pesquisa: a presença e os tipos de violência cometidos contra o(a) idoso(a); as motivações que impeliram à prática da violência contra o(a) idoso(a); como se caracteriza o relacionamento entre eles; os sentimentos experimentados e as necessidades sentidas pelos agressores. As perguntas foram as seguintes: 1) O que aconteceu para o(a) senhor(a) ser denunciado(a)? (Verificou-se a presença e tipos de violência); 2) Que fatores contribuíram para a ocorrência deste fato?; 3) Como que é o seu relacionamento como o(a) idoso(a)? Existiu ou existe história de violência na família?; 4) Quais os sentimentos experimentados pelo(a) senhor(a) nesta situação?; 5) Quais as necessidades sentidas pelo(a) senhor(a) em relação a este problema?

\section{Procedimentos de coleta de dados}

Inicialmente, foram solicitadas autorizações nas Instituições Judiciárias já referidas, que foram utilizadas como cenário para realização da pesquisa. Em seguida, o projeto foi aprovado pelo 
Comitê de Ética em Pesquisa da Universidade Católica de Pernambuco, sob o número 206.785/2013. Obtida a aprovação pelo Comitê de Ética, iniciou-se a pesquisa de campo, que foi realizada em duas etapas. A primeira etapa, no Juizado Especial Criminal do Idoso, e a segunda etapa, na $1^{\text {a }}$ Vara de Violência Doméstica e Familiar contra Mulher, do Recife. Os participantes, após leitura e assinatura do Termo de Consentimento Livre e Esclarecido (TCLE), responderam ao questionário sociodemográfico e ao roteiro de entrevista semiestruturada.

Foi enfatizado que a participação voluntária não tinha relação com o processo do participante com a Justiça, sendo garantido o sigilo das informações. Todos os participantes foram informados da gravação da entrevista e da anotação e transcrição dos conteúdos. Para cada um foi atribuído um nome fictício com o objetivo de manter o sigilo sobre sua identidade. A primeira autora foi orientada pela segunda sobre como abordar os agressores. Houve recusa de 26 agressores em participar, embora a pesquisadora tenha envidado esforços para incentivá-los, no sentido de explicar a importância da escuta e acolhimento para eles.

\section{Procedimentos de análise dos dados}

Os dados sociodemográficos, tanto os dos participantes como os dos idosos, apresentados em quadros sob a forma de frequência. Após a coleta e a transcrição das entrevistas, passou-se à análise de conteúdo temática. Conforme Minayo (2010, p. 316-318), fazer uma análise temática consiste em descobrir os núcleos de sentido que compõem uma comunicação, cuja presença ou frequência signifiquem alguma coisa para o objeto analítico visado. Ela consiste em três fases: pré-análise (composta de leitura flutuante, organização do corpus e formulação de hipóteses); exploração do material (consiste em encontrar as categorias de análise) e análise e interpretação do material.

\section{Resultados}

Nesta seção serão apresentados os resultados obtidos, iniciando-se pela frequência dos dados sociodemográficos dos participantes e dos idosos (Quadros1 e 2) e, em seguida, as respostas às entrevistas.

\section{Núcleos de sentido}

Os núcleos de sentido foram retirados através das respostas ao roteiro de entrevista semiestruturada, em consonância com os objetivos da pesquisa, sistematizados a seguir:

\section{Presença e tipos de violência}

Observou-se que houve a presença de violência. Prevaleceram as agressões verbais e as físicas que aconteceram concomitantemente nos litígios. Geralmente as situações que culminaram em violência iniciaram-se com as verbais e terminaram desembocando nas físicas:

[...] No processo está escrito que eu humilhei, ameacei e agredi fisicamente meu pai e me apropriei do documento da casa. Mas eu não fiz isso. É a mulher que cuida dele (da casa dele) que bota as coisas na cabeça dele (Lavanda, 54 anos, filha).

[...] Sou uma filha rebelde, mas nunca bati, porque quem bate em mãe e pai são os filhos amaldiçoados e eu nunca fiz isso. [...] Eu cheguei de madrugada e estava sem a chave, ela (a mãe) acordou para abrir a porta e brigou comigo, e aí nós discutimos, aí ela tentou dar em mim, eu a empurrei e ela caiu no sofá (Hortência, 35 anos, filha).

[...] Discutimos por causa da televisão, porque ela queria um canal e eu queria outro, mas eu não bati, eu encostei uma garrafa na cabeça dela e forcei. O que acontece é que, por conta disso, ela e essa minha irmã que tá morando com ela prestou essa queixa. E é difícil porque uma vez que ela é mãe, ela é genitora, aí fica difícil [...] (Cardo, 47 anos, filho).

\section{Motivações que impeliram à prática da violência}

O uso abusivo de álcool; a proximidade física no sentido da falta de espaço físico dificultando a privacidade, por morar na mesma casa ou quintal; a dependência financeira do agressor em relação ao idoso; relacionamento permeado de violência por ocorrência ou não de agressão sofrida na família, especialmente por parte do(a) idoso(a). Nesta temática, observou-se que, dos 13 participantes, apenas dois 
disseram não ter sofrido violência física, psicológica ou sexual na família:

[...] O problema é que, quando eu bebo e vou passear, minha mulher não gosta. Quando eu chego já venho com a cara cheia (de bebida alcoólica), minha mulher fica muito braba comigo e vem pra cima de mim me bater, e eu também brigo com ela. Como moramos no mesmo quintal, aí meu sogro vê e vem se meter e a gente acaba discutindo também. Ele pega um pedaço de pau e vem prá cima de mim, aí não dá certo não. Ele não gosta e denuncia a gente aqui. Sempre foi assim (Alecrim, 57 anos, genro).

[...] A situação nunca foi boa, sempre meu sogro brigou muito com meu marido e comigo tam- bém. Mas se agravou quando minha sogra morreu e meu sogro quis nos expulsar de casa. Ele quer que a gente desocupe a casa para ele colocar as prostitutas dentro de casa. Nós estamos desempregados e não temos para onde ir (se emocionou). Depois que minha sogra morreu, ele fechou com tijolos a porta de nosso quarto que dava para dentro da casa, abrimos uma saída na parede. Ele tomou tudo que a gente tinha: cama, televisão, tudo. Passamos fome, ele cortou nossa luz (chorou). Nosso quarto onde moramos é bem pequenininho (Açucena, 48 anos, nora).

[...] No passado, sofri (agressões) físicas e verbais. Ele deu um tiro em mim, a sorte foi que não bateu. Mas apanhei muito na cara. Quando estava para descansar de minha filha ele queria fazer sexo e eu

Quadro 1

Dados sociodemográficos dos agressores.

\begin{tabular}{|c|c|c|c|c|c|}
\hline Dado & Frequência & Dado & Frequência & Dado & Frequência \\
\hline Sexo & & Profissão & & Usuário de droga & \\
\hline Masculino & 6 & Doméstica & 2 & Sim & 9 \\
\hline Feminino & 7 & Diversos & 11 & Não & 3 \\
\hline Idade & & $\begin{array}{l}\text { Situação } \\
\text { Profissional }\end{array}$ & & Depende do idoso & \\
\hline 20 a 40 anos & 5 & Empregado & 8 & Sim & 3 \\
\hline 40 a 60 anos & 7 & Desempregado & 5 & Não & 10 \\
\hline 60 a 80 anos & 1 & & & & \\
\hline Estado civil & & Desempregado & & Parentesco com o idoso & \\
\hline Solteiro & 3 & Sem salário & 5 & Filho(a) & 6 \\
\hline Casado & 4 & Um & 1 & Genro/nora & 3 \\
\hline \multirow[t]{3}{*}{ União estável } & 6 & Dois & 4 & Irmão(a) & 2 \\
\hline & & Quatro & 2 & Cunhado(a) & 1 \\
\hline & & Dez & 1 & Esposo(a) & 1 \\
\hline Grau de escolaridade & & Religião & & Proximidade & \\
\hline $1^{\circ}$ grau incompleto & 3 & Católico & 8 & Reside com o idoso & 10 \\
\hline $2^{\circ}$ grau incompleto & 1 & Evangélico & 3 & Não reside com o idoso & 3 \\
\hline $2^{\circ}$ grau completo & 5 & Espírita & 1 & & \\
\hline $3^{\circ}$ grau incompleto & 1 & Ateu & 1 & & \\
\hline $3^{\circ}$ grau completo & 3 & & & & \\
\hline
\end{tabular}


Quadro 2

Dados sociodemográficos dos idosos agredidos.

\begin{tabular}{|c|c|c|c|c|c|}
\hline Dado & Frequência & Dado & Frequência & Dado & Frequência \\
\hline Sexo & & Profissão & & Proximidade & \\
\hline Masculino & 8 & Aposentado & 13 & Reside com o agressor & 10 \\
\hline Feminino & 5 & & & Não reside com o agressor & 3 \\
\hline Idade & & $\begin{array}{l}\text { Parentesco como } \\
\text { agressor }\end{array}$ & & Estado Civil & \\
\hline 60 a 70 anos & & Pai/mãe(a) & & Casado & 1 \\
\hline \multirow[t]{4}{*}{70 a 80 anos } & & Sogro(a) & & Viúvo & 12 \\
\hline & & Irmão(a) & & & \\
\hline & & Cunhado(a) & & & \\
\hline & & Esposo(a) & & & \\
\hline
\end{tabular}

não queria e aí ele me deu um tapa no rosto e me obrigou a transar e eu tive que fazer para satisfazer a ele. Atualmente ele vinha me agredindo verbal $\mathrm{e}$ psicologicamente. Não houve violência de minha parte (Flor de Liz, 63 anos, esposa).

[...] Mas física, eu já sofri quando criança. [...] Ela (referindo-se à mãe) deu uma surra em mim, amarrou meus braços no telhado e me deixou numa posição que só desse para eu me abaixar e fazer xixi no penico. Apagou todas as luzes, que era um vão só, acendeu uma vela num pires e ficou lá me observando (Genciana, 38 anos, filha).

\section{Sentimentos experimentados na situação atual}

Foi frequente a menção a sentimentos de tristeza, decepção, impaciência, raiva, injustiça, angústia, trazendo como consequências dificuldade para dormir, choro, raiva, solidão.

[...] Não tenho paz, não durmo direito, só vivo pensando nisso. Vivo muito triste porque ela (a irmã do agressor) não deixa eu ir ver meu pai (Cravo Roxo, 51 anos, irmão).

[...] Eu, esse assunto eu não gosto nem de mexer muito, me comove muito. Eu jamais pensei que estaria vivendo uma situação dessas (chorou).
Eu não sei nem te explicar. Eu me sinto só. Tipo assim, a minha graça era a minha mãe, e a minha irmã, mas hoje eu não tenho ninguém. De família eu não tenho ninguém, ninguém. Então assim, foi o que de pior podia ter acontecido comigo (Genciana, 38 anos, filha).

[...] De tristeza, decepção. No final da vida estou sofrendo isso. Com meus filhos casados era agora para estarmos juntos, felizes, aproveitando o resto de nossa vida. Hoje moro sozinha (chorou) (Flor de Liz, 63 anos, esposa).

\section{Necessidades sentidas}

Sobressaiu-se o desejo de que o processo fosse encerrado, que eles possam voltar à vida normal e que voltassem a conviver com o(a) idoso(a):

[...] Que encerrasse isso (o processo, o litígio) há muito tempo (Alecrim, 57 anos, genro).

[...] Necessidade de viver novamente, de voltar à minha vida social, de liberdade (Acônito, 30 anos, filho).

[...] É isso aí, são várias, né? Como eu falei você sente falta da convivência da família, e os filhos, afinal de contas ela é avó, né (chorou e continuou falando e chorando). Eu queria que tivesse tudo bem né, que a gente tivesse junto, mas eu ainda 
penso nisso, é só uma questão de tempo ainda. Eu por mim assim, tipo um pé atrás, esperando o tempo passar pra ver o que é que se resolve, né? (Gerânio Escuro, 45 anos, filho).

\section{Discussão}

No que se refere à presença de violência contra o idoso(a) observou-se que os participantes cometeram a violência por razões várias, mas não se percebem serem agressores em potencial. Isso nos leva a pensar sobre o que o agressor entende por agressão, pois a maioria viveu num ambiente e contexto de violência e a sofreu também, aprendeu a relacionar-se dessa forma, reproduzindo-a. Contudo, sabe-se que existem outras formas de resolver situações desconfortáveis, sem se utilizar da reedição do maltrato. Corroborando com o que foi apontado por Papalia et al. (2006) e Minayo (2005; 2008), por vezes o agressor foi vítima de violência e pode descarregar no idoso sentimentos de ambivalência, mágoa e revolta, colocando o idoso num lugar em que um dia esteve e que talvez ainda esteja.

Quanto aos tipos de violência cometidas contra o idoso (a) prevaleceram as agressões verbais seguidas das físicas, sendo que geralmente as agressões verbais estão implícitas nas demais formas de violência. Esses resultados também foram verificados em pesquisas realizadas por Berzins e Watanabe (2010); Faleiros (2013); Minayo (2008); Ministério Público de Pernambuco (2012).

Constata-se que pode haver diferenças nos tipos de violência praticadas de acordo com estados, região do país ou outros países. No Canadá, mais da metade dos casos denunciados foi de abandono (Dias, 2005). No Brasil, em linhas gerais, pesquisa realizada por Pasinato et al. (2006) evidenciou que se sobressaíram o abandono e as agressões físicas. Correia et al. (2012) e Nogueira et al. (2011) destacam que estudos realizados em outros países e com outras populações-alvo indicam a ocorrência concomitante de vários tipos de maus-tratos, em especial, a simultaneidade entre os maus-tratos físicos e psicológicos.

Entre as motivações que impelem à prática da violência contra o idoso (a) destacou-se o uso abusivo de álcool, que foi referido por nove entre os treze familiares investigados, constitui-se importante fator de risco para ocorrência da violência. A literatura refere que mais de $50 \%$ dos idosos cujos familiares são usuários de álcool/drogas sofrem algum tipo de abuso físico ou emocional (Minayo, 2008; Minayo et al., 2010). Isso significa dizer que, quando a pessoa que reside com o idoso apresenta problemas de alcoolismo, dependência de drogas ou dificuldades emocionais, aumenta o risco de maus-tratos (Berzins \& Watanabe, 2010; Brien, 2008; Faleiros, 2013; Wanderbroocke, \& Ocampo Moré, 2013).

A proximidade física foi verificada em dez dos participantes. Esse dado corrobora a literatura que pressupõe essa condição como fator de risco para violência. A convivência entre três ou mais gerações favorece o choque entre elas devido a dificuldades, tais como: falta de espaço físico, desemprego estrutural, necessidade de aperfeiçoamento profissional por parte dos filhos, novos arranjos familiares, aumento do número de divórcios e separações, que propiciam o retorno dos filhos adultos à casa de seus pais, desenvolvendo uma dependência financeira e emocional dos mesmos (Araújo, Amaral, Sá, Azevedo, \& Lobo Filho, 2012; Faleiros \& Brito, 2009; Figueiredo, Souza, Njaine, \& Ribeiro, 2010; Nogueira et al., 2011).

Nesse sentido, o convívio plurigeracional ou multigeracional não pode ser visto como garantia de velhice bem-sucedida, e nem mesmo sinal de relações mais amistosas entre as sucessivas gerações (Lourenço et al., 2012). Camarano e El Ghouri (2003) referem que esse tipo de arranjo familiar favorece mais as gerações dos filhos e dos netos do que a dos idosos, que ficam sobrecarregados, em níveis financeiro e emocional, nesta situação. Face ao exposto, vê-se a complexidade do fenômeno que motiva a violência ao idoso (Vasconcellos, 2003) e a interdependência entre diversos fatores, como postula a teoria sistêmica (Bertalanffy, 2008).

A dependência financeira do(a) agressor(a) em relação ao idoso(a) constitui fator importante para o risco de violência contra pessoa idosa. Três participantes dependem, financeiramente, diretamente do idoso, e outros sete, indiretamente, por dividir o mesmo espaço físico (casa ou quintal). Este achado corrobora a literatura que indica a falta de recursos econômicos como provocadora de desentendimento com os filhos. Relacionando com os sistemas mais amplos, encontra-se que os contextos sociopolítico e econômico funcionam como um processo que agride o modelo de família e atinge a identidade pessoal e familiar, provocando desagregações, desajustes e 
desequilíbrios (Correia et al., 2012; Faleiros \& Brito, 2009; Menezes, 2010; Minayo, 2008; Papalia et al., 2006). Dias (2005), afirma que os agressores são mais dependentes do idoso, do que o contrário.

O relacionamento permeado de violência entre ambos inclui os desentendimentos anteriores à ocorrência da agressão e a vivência num contexto de violência. Szelbracikowski e Dessen (2005) referem que a agressão pode ser determinada por múltiplos fatores que interagem entre si, distinguindo os ambientes familiares, os aspectos biológicos e os demográficos. Ambientes familiares adversos, práticas parentais inadequadas, rejeição, as transições familiares não normativas (desemprego, separações, doenças) e os traços de personalidade dos pais, dentre outros fatores, podem expor o indivíduo a situações de risco. Os aspectos biológicos relacionam-se a fatores genéticos, hormonais, alimentares, eventos perinatais e outros mecanismos que podem levar o indivíduo a reagir ao seu ambiente de forma negativa. Os fatores demográficos dizem respeito ao nível econômico, ao status parental, ao tamanho da família e à etnia (Sousa et al., 2010).

Szelbracikowski e Dessen (2005) afirmam que pessoas agressivas costumam pertencer a famílias com disciplina inconsistente, nas quais são rejeitadas ou acometidas por punições severas. Depressão materna e os traços de personalidade dos pais também contribuem para que a criança se torne ou não agressiva. No que se refere aos fatores sociais, é importante considerar a vizinhança e a comunidade na qual a criança agressiva está inserida. Em certas vizinhanças e comunidades, cujos atos de extrema violência são comuns, a agressão física e a verbal podem ser explicadas como uma estratégia de sobrevivência, ou seja, como uma resposta adaptativa ao ambiente local. Pontuam, ainda, que pessoas residentes em comunidades urbanas de baixa renda são seriamente afetadas pela ascensão, sem precedentes, de uma comunidade em geral violenta, pobre e com história de abuso de droga. Elas são também afetadas pela ausência de suporte social no que diz respeito a apoio e recursos para sanar as mínimas necessidades de saúde física, mental, de preparação para o mercado de trabalho e também fornecer emprego, pois são menos favorecidas pelas contingências sociais e vivem à margem da sociedade. Todo esse contexto faz da violência um fenômeno de alta complexidade, que merece ser refletido com mais seriedade, trabalhan- do-se com a prevenção por meio da criação, implantação e implementação de políticas públicas que atendam a esse segmento, e que considerem a necessidade de orientar as famílias sobre as vicissitudes do envelhecimento e suas consequências, contribuindo para uma pedagogia do cuidado e compreensão em relação à pessoa idosa.

Fonseca e Gonçalves (2003) afirmam que, numa visão de homem biopsicossocial e cultural, é importante ressaltar, no que se refere às influências culturais, o quanto a cultura de uma sociedade ou nação está presente na forma de permitir, controlar e criar meios de evitar atos agressivos. Em outras palavras, a violência estrutural pode ser o fio condutor da violência que atinge o homem e a família, podendo considerar-se esse fenômeno como um processo de intercâmbio com o meio. Nesse sentido, Bertalanffy (2008) refere que uma das propriedades do sistema é o intercâmbio com o meio, e como sistema aberto que é, a família interage continuamente com o meio ambiente, dele sofrendo influência como também influenciando-o. Vasconcellos (2003), por sua vez, propõe uma forma sistêmica de observar o fenômeno, partindo do pressuposto da simplicidade para o da complexidade, implicando ampliar o foco e olhar para a situação contextualizada.

A ocorrência ou não de agressão sofrida na família especialmente por parte do(a) idoso(a). Nessa temática, observou-se que, dos 13 participantes, apenas dois disseram não ter sofrido violências física, psicológica ou sexual na família. Minayo (2007) afirma que a qualidade da relação prévia entre familiar e idoso parece ser um indicador confiável e assinala que a falta de vínculos significativos ou "vínculos frouxos" desponta como causa mais frequente da violência.

A ocorrência de violência demonstra que o agressor que sofreu agressões e violência no passado tende a repeti-la nos seus relacionamentos familiares através da retroalimentação negativa, possivelmente como uma forma de restabelecer a homeostase familiar (Bertalanffy, 2008). Todavia, a violência não justifica a violência, pois os indivíduos podem dar um sentido novo às experiências negativas sofridas sem empregar esse mecanismo de enfrentamento. Pinto et al. (2013) confirmam que, na maioria das famílias com problemas de violência, seus membros não possuem repertório interpessoal pró-social para lidar com as dificuldades. Nesse sentido, a violência seria a forma que eles encontram de expressar seus sentimentos. 
Ainda em relação à temática, Dias (2005) remete esta questão à perspectiva da transmissão intergeracional do comportamento violento. Argumenta que a exposição à violência durante a infância, a experiência de vitimação durante esse período e o testemunho na família da prática de maus-tratos aos membros mais velhos conduzem à aprendizagem de comportamentos abusivos e, provavelmente, à sua reprodução. Essa teoria postula que as pessoas que cometem abusos com os idosos, na maioria das vezes, foram educadas em contextos familiares violentos. A esse respeito, Faleiros (2013) destaca que a família é o locus em que se concentra o maior número de violência praticada contra a pessoa idosa.

Novo e Lopes (2010) ressaltam que há indivíduos velhos que são violentos e se manifestam de forma agressiva em suas relações. Alves (1986), por sua vez, refere que existem vítimas potenciais: os de personalidades insuportáveis, criadoras de casos, e que levam ao desespero aqueles com quem convivem. Ainda sobre esse aspecto, Berzins e Watanabe (2010), Côrte (2010), Minayo (2008), Novo e Lopes (2010) destacam que é importante considerar que o Estatuto do Idoso, apesar de ter representado um avanço nas conquistas dos direitos desse segmento etário, em alguns casos tornou-se, para alguns velhos, artefato de chantagem e ameaça. Isso contradiz a percepção que se tem da pessoa idosa que, geralmente, é colocada no lugar de vítima. Por outro lado, nesses casos, é importante considerar que existem conflitos familiares que também podem levar o idoso a adotar comportamentos violentos, como também que ele pode ficar agressivo por causa de processo de demência que a própria família não reconhece. Desse modo, não se pode generalizar que os idosos estão se ancorando numa lei que os defende para agredir, até porque muitos não conhecem o Estatuto do Idoso, e nem mesmo sabem ler.

Quanto aos sentimentos experimentados com a situação, Amaral (2001) pontua que a situação alvo de litígio, em geral, atinge os bens da personalidade, tais como a honra, a liberdade, a saúde, a integridade psicológica, causando dor, sofrimento, tristeza, vexame e humilhação às partes envolvidas no processo. Acrescenta-se que, no caso em que a situação envolve familiares, tais sentimentos são mais fortes devido aos laços de intimidade e convivência que caracterizam essas relações, podendo levar os envolvidos a uma verdadeira situação de luto, conforme pudemos constatar nesta pesquisa.

Entre as necessidades sentidas pelos agressores sobressaiu-se o desejo de que o processo fosse encerrado e, consequentemente, que eles pudessem voltar à sua vida normal, ter uma casa, um emprego, um negócio próprio e estudar. Mas também expressaram o desejo de reconciliação com o idoso, com o fim das desavenças e uma vida feliz, o que mostra a ambivalência de sentimentos que perpassa essa situação.

\section{Considerações finais}

Este trabalho se caracteriza como um estudo preliminar porque trata de uma temática ainda com escassa quantidade de estudos, no sentido de pesquisas que enfoquem exclusivamente a pessoa do agressor familiar do idoso, e que não é seu cuidador. Percebemos que, de fato, ocorreu a violência praticada contra o idoso, embora se observe a dificuldade dos participantes em admitir. Dentre as motivações que a impeliram, sobressaíram-se o uso de álcool, a proximidade física e a dependência financeira do agressor em relação ao idoso; quanto às motivações, relacionamentos permeados de violência foi a razão mais evidente; os sentimentos experimentados foram revelados como tristeza, decepção, raiva, injustiça, angústia e revolta; as necessidades sentidas perpassaram pelo desejo de que o processo fosse encerrado, com a volta a vida normal e a convivência com o idoso.

É importante destacar a ocorrência de conflitos ao longo do tempo, que se potencializam na velhice. Isso ocorre, provavelmente, também em decorrência dos preconceitos ainda existentes no imaginário social acerca dessa fase do ciclo vital. Aliado a esse fato, observou-se que o idoso também contribui para a ocorrência da violência, devido às exigências que faz, impaciência e até mesmo a um possível processo de demência ou doença mental que não é compreendido pelos familiares. Nesse sentido, é pertinente abordar a importância da capacitação e orientação das famílias acerca do processo de envelhecimento e suas vicissitudes, considerando que a velhice é uma fase do ciclo vital na qual a pessoa está mais fragilizada (Neri, 2013).

A presente pesquisa revelou a falta de preparação dos agressores para o envelhecimento dos pais e demais parentes. Nesse sentido, faz-se necessário implementar campanhas de esclarecimento 
nas escolas (desde o ensino fundamental), famílias, comunidades e mídias para que o processo de envelhecimento seja melhor conhecido, tendo em vista o crescente contingente de pessoas idosas no nosso país. É importante, sobretudo, elaborar intervenções para acolher o agressor, concedendo-lhe a oportunidade de ressignificar seu ato de violência contra a pessoa idosa, contribuindo para o restabelecimento da homeostase na relação entre idoso e agressor.

O Estatuto do Idoso (Brasil, 2003), sem dúvida, é um documento que protege e garante minimamente os direitos da pessoa idosa, mas, paradoxalmente, tem também sido usado por alguns idosos como uma arma com a qual se defendem contra qualquer ato praticado pelos familiares. Observou-se que isso foi frequente na fala dos participantes que sofreram agressão por parte do idoso. Há indivíduos idosos que são violentos e se manifestam de forma agressiva em suas relações. Nesse sentido, é necessário que os profissionais que lidam com essa questão procurem investigar todo o contexto que cerca a situação e usem de discernimento e cautela na investigação da denúncia para que não se cometa injustiça nem de um lado, nem do outro.

As limitações da pesquisa dizem respeito principalmente a ser um tema difícil de ser investigado devido aos tabus que o cercam, pois traz à tona questões de família que as pessoas temem ou envergonham-se para falar, principalmente quando estão em um espaço jurídico onde estão sendo processadas. É possível que a recusa a participar, por parte de vários indivíduos convidados, tenha a ver com essas questões, muito embora se tivesse garantido a eles o sigilo

\section{Referências}

Abath, M. B., Leal, M. C. C., \& Melo Filho, D. A. (2012). Fatores associados à violência doméstica contra a pessoa idosa. Revista Brasileira de Geriatria e Gerontologia, 15(2), 305-314. doi:10.1590/S1809-98232012000200013

Agressor. (2015). In Dicio: dicionário online de português. Recuperado de http://www.dicio.com.br/agressor/

Alves, R. B. (1986). Criminologia. Rio de Janeiro, RJ: Forense. sobre as informações e a não relação entre a pesquisa o e processo a que estavam respondendo.

Os pontos fortes da pesquisa se relacionam a ser um tema extremamente relevante porque se acredita que ela acrescenta algo aos estudos sobre o envelhecimento, especialmente no que se refere à violência contra a pessoa idosa na família, num país em que a população envelhece a passos largos. Também porque focalizou uma faceta desse tipo de violência ainda pouco estudada que é a pessoa considerada como agressora. Nesse sentido, propiciar um espaço de escuta sobre suas motivações, os sentimentos e as necessidades sentidas por elas, possibilitou concluir que antes de condená-la é preciso ouvi-la e compreendê-la, pois percebeu-se que estavam em um estado de muito sofrimento, embora nada justifique a violência.

Futuras pesquisas necessitam ser empreendidas no sentido de aprofundar os estudos sobre a temática e lhe dar visibilidade, ampliando a quantidade de participantes, bem como ouvindo os próprios idosos agredidos, e os profissionais que atendem tais situações. Só assim se poderá ter uma visão sistêmica do problema e enfrentá-lo em sua complexidade.

Por fim, destacamos que os abusos e as negligências que se perpetuam contra os idosos devido ao choque entre gerações, problemas de espaço físico e dificuldades financeiras, entre outros, se somam a um imaginário social que considera a velhice como "decadência" e os idosos como "ultrapassados" e "descartáveis". Essas situações e preconceitos precisam ser combatidos e fazer parte de campanhas educativas, bem como das políticas públicas de enfrentamento à violência.

Amaral, S. M. M. (2001). Prisão ilegal: a responsabilidade civil do estado e o decorrente dever de indenizar pelos danos morais: quantificação dos valores indenizatórios. Jus Navigandi, 51(6), 1-2. Recuperado de http://jus.com.br/artigos/2273

Araújo, L. F., Amaral, E. B., Sá, E. C. N., Azevedo, R. L. W., \& Lobo Filho, J. G. (2012). Violência contra a pessoa idosa: representações sociais entre adolescentes do Arquipélago de Fernando de Noronha-PE. Psicologia \& Sociedade, 24(1), 104-111. doi:10.1590/S0102-71822012000100012 
Barcelos, E. M., \& Madureira, M. D. S. (2013).Violência contra o idoso. In F. Chaimowicz (Ed.), Saúde do idoso (pp.132-141). Belo Horizonte: UFMG.

Bertalanffy, L. (2008). Teoria geral dos sistemas: fundamentos, desenvolvimento e aplicações. Petrópolis, RJ: Vozes.

Berzins, M. V., \& Watanabe, H. A. W. (2010). A violência doméstica contra a pessoa idosa. In D. V.S. Falcão (Ed.), A família e o idoso: desafios da contemporaneidade (pp.151-170). Campinas, SP: Papirus.

Brasil. (2003). Lei no 10.741, de $1^{\circ}$ de outubro de 2003. Dispõe sobre o Estatuto do Idoso e dá outras providências. Diário Oficial da União, 3 de outubro.

Brasil. (2005). Ministério da Saúde. Secretaria de Vigilância em Saúde. Departamento de Análise de Situação de Saúde. Política nacional de redução da morbimortalidade por acidentes e violências: Portaria MS/GM n.o 737 de 16/5/01, publicada no DOU n. ${ }^{\circ} 96$ seção 1E de 18/5/01 (2a ed.) Brasília, DF: Ministério da Saúde.

Brien, J. G. O'. (2008). Abuso de los ancianos. In R. J. Ham \& P. D. Sloane (Eds.), Atenção primária em geriatria: casos clínicos (pp. 462- 463). Madrid: Mosby.

Camarano, A. A., \& El Ghouri, S. K. (2003). Famílias com idosos: ninhos vazios? (Texto para discussão, vol. 95). Brasília, DF: Instituto de Pesquisa Econômica Aplicada.

Côrte, B. (2010). O idoso como agente do crime. In M. V. Berzins, \&W. Malagutti (Eds.), Rompendo o silêncio: faces da violência na velhice (pp.253-273). São Paulo, SP: Martinari.

Correia, T. M. P., Leal, M. C. C., Marques, A. P. O., Salgado, R. A. G., \& Melo, H. M. A. (2012). Perfil dos idosos em situação de violência atendidos em serviço de emergência em Recife-PE. Revista Brasileira de Geriatria e Gerontologia, 15(3), 529-536. doi:10.1590/S1809-98232012000300013

Dias, I. (2005). Envelhecimento e violência contra os idosos. Sociologia, 15, 249-273. Recuperado de http://web.letras.up.pt/modulo65mais/index_files/Page1532.htm

Faleiros, V. P. (2013). O mapa da violência contra a pessoa idosa no Distrito Federal. Brasília, DF: MPDFT.

Faleiros, V. P. (2007). Violência contra a pessoa idosa: ocorrências, vítimas e agressores. Brasília, DF: Universa.
Faleiros, V. P., \& Brito, D. O. (2009). Representações da violência intrafamiliar por idosas e idosos. In V.P. Faleiros, A.M.L. Loureiro \& M. A. Penso (Eds.), O conluio do silêncio: a violência intrafamiliar contra a pessoa idosa (pp.2-19). São Paulo, SP: Roca.

Figueiredo, A. E. B., Souza, E. R., Njaine, K., \& Ribeiro, A. P. (2010). Violência contra a pessoa idosa. In M.V. Berzins, \& W. Malagutti (Eds.), Rompendo o silêncio: faces da violência na velhice (pp.109-121). São Paulo, SP: Martinari.

Fonseca, M. M., \& Gonçalves, H. S. (2003). Violência contra o idoso: suportes legais para a intervenção. Interação em Psicologia, 7(2), 121-128. doi:10.5380/psi.v7i2.3230

Gaioli, C. C. L. O., \& Rodrigues, R. A. P. (2008). Ocorrência de maus tratos em idosos no domicílio. Revista Latino-americana de Enfermagem, 16(3), 465-470. doi:10.1590/S0104-11692008000300021

Gondim, R. M. F., \& Costa, L.M. Violência contra o idoso. (2006). In D. V. S. Falcão, \& C. M. S. B. Dias (Eds.), Maturidade e velhice: pesquisas e intervenções psicológicas (Vol. 1; pp. 169-191). São Paulo, SP: Casa do Psicólogo.

Grossi, P. K., \& Souza, M. R. (2003). Os idosos e a violência inviabilizada na família. Textos \& Contextos, 2(2), 1-14. Recuperado de http://revistaseletronicas. pucrs.br/ojs/index.php/fass/article/view/967/747

Leite, M., Hildebrandt, L., \& Santos, A. (2008). Maus tratos a idosos no domicílio: concepções de familiares. Revista Brasileira de Geriatria e Gerontologia, 11(2), 209-221.

Lourenço, L. M., Mota, D.C.B., Carvalho, R. G., Gebara, C.F.P., \& Ronzani, T. M. (2012). Crenças dos profissionais da Atenção Primária à Saúde de Juiz de Fora em relação à violência doméstica contra idosos. Estudos de Psicologia (Campinas), 29(3), 427-436. doi:10.1590/S0103-166X2012000300012

Menezes, M. R. (2010). Violência contra idosos: é preciso se importar! In M. V. Berzins, \& W. Malagutti (Eds.), Rompendo o silêncio: faces da violência na velhice (pp. 25-28). São Paulo, SP: Martinari.

Minayo, M. C. S. (2010). O desafio do conhecimento: pesquisa qualitativa em saúde. São Paulo, SP: Hucitec. Minayo, M. C. S. (2007). Violência contra a pessoa idosa: o direito pelo avesso. In M. Papaléo Netto (Ed.), Tratado de gerontologia (pp. 199- 210). (2a ed. rev. ampl.). São Paulo, SP: Atheneu. 
Minayo, M. C. S. (2008). Violência e maus-tratos contra a pessoa idosa: é possível prevenir e superar. In T. Born (Ed.), Cuidar melhor e evitar a violência: manual do cuidador da pessoa idosa (pp.38-45). Brasília, DF: Secretaria Especial dos Direitos Humanos.

Minayo, M. C. S. (2005). Violência: um velho-novo desafio para a atenção à saúde. Revista Brasileira de Educação Médica, 29(1), 55-63. Recuperado de http:// www.bvsde.paho.org/bvsacd/cd51/desafio.pdf

Minayo, M. C. S., Souza, E. R., \& Paula, D. R. (2010). Revisão sistemática da produção acadêmica brasileira sobre causas externas e violências contra a pessoa idosa. Ciência \& Saúde Coletiva, 15(6), 2709-2718. doi:10.1590/S1413-81232010000600010

Ministério Público de Pernambuco. (2012). Caravana da Cidadania. Dia mundial de enfrentamento à violência contra a pessoa idosa. Recife, PE: Centro Integrado de Cidadania. Recuperado de http://www. mppe.mp.br/caravanadapessoaidosa $/ \mathrm{p}=60$

Muchembled, R. (2012). História da violência: do fim da Idade Média aos nossos dias. Rio de Janeiro, RJ: Forense Universitária.

Neri, A. L. (Org.). (2013). Fragilidade e qualidade de vida na velhice (Coleção Velhice e sociedade). Campinas, SP: Alínea.

Novo, A. L. M. S., \& Lopes, R. G. C. (2010). O outro lado da moeda: velhos violentos. In M.V. Berzins \& W. Malagutti (Eds.), Rompendo o silêncio: faces da violência na velhice (pp. 239-252). São Paulo, SP: Martinari.

Nogueira, C. F., Freitas, M. C., \& Almeida, P. C. (2011). Violência contra idosos no município de Fortaleza, CE: uma análise documental. Revista Brasileira de Geriatria e Gerontologia, 14(3), 543-554. doi:10.1590/S1809-98232011000300014

Papalia, D. E., Olds, S.W., \& Feldman, R. D. (2006). Desenvolvimento humano (8a. ed). Porto Alegre, RS: Artmed.

Pasinato, M. T., Camarano, A. A., \& Machado, L. (2006). Idosos vítimas de maus tratos domésticos: estudo exploratório das informações dos serviços de denúncia. Rio de Janeiro: Instituto de Pesquisa Econômica Aplicada.

Pinto, F. N. F. R., Barham, E. J., \& Albuquerque, P. P.(2013). Idosos vítimas de violência: fatores sócio demográficos e subsídios para futuras intervenções.
Revista Estudos de Psicologia, 13(3), 1159-1181. Recuperado de http://www.e-publicacoes.uerj.br/index.php/revispsi/article/view/8610/7546

Silva, A. C. L. G., Coelho, E. B. S., \& Moretti-Pires, R. O. (2014). O que se sabe sobre o homem autor de violência contra a parceira íntima: uma revisão sistemática. Revista Panamericana de Salud Publica, . 35(4), 278-83.

Sousa, J. D., White, H.J., Soares, L. M, Nicolosi, G.T., Cintra, F. A., \& D'Elboux, M. J. (2010). Maus-tratos contra idosos: atualização dos estudos brasileiros. Revista. Brasileira de Geriatria e Gerontologia, 13(2), 321-328. doi:10.1590/S1809-98232010000200016

Szelbracikowski, A., \& Dessen, M. A. (2005). Compreendendo a agressão na perspectiva do desenvolvimento humano. In M. A. Dessen \& A. L. Costa Junior (Eds), A ciência do desenvolvimento humano: tendências atuais e perspectivas futuras (pp. 231-246). Porto Alegre, RS: Artmed.

Vasconcellos, M. J. E. (2003). Pensamento sistêmico: o novo paradigma da ciência. Campinas, SP: Papirus.

Wanderbroocke, A. C. N. S., \& Ocampo Moré, C. L. O. (2013). Estrutura e funcionamento familiar e a violência contra idosos. Psicologia Argumento, 31(74), 147- 268. Recuperado de http://www2.pucpr.br/reol/pb/index.php/pa?ddl=12231\&dd99=view\&dd98=pb

Yan, E., Chan, K.-L., \& Tiwari, A. (2014). A systematic review of prevalence and risk factors for elder abuse. Trauma, Violence, \& Abuse, 16(2), 199-219. doi:10.1177/1524838014555033

Cirlene Francisca Sales Silva

Doutoranda. Universidade Católica de Pernambuco, Recife - PE. Brasil.

E-mail: cirlene.psicologa@gmail.com

Cristina Maria de Souza Brito Dias

Doutora. Docente da Universidade Católica de Pernambuco, Recife - PE. Brasil.

E-mail: cristina.msbd@gmail.com

Endereço para envio de correspondência: Universidade Católica de Pernambuco, Programa de Pós-Graduação em Psicologia Clínica. Rua do Príncipe, 526. Boa Vista. CEP: 50050-900.

Recife - PE. Brasil. 
Recebido 23/10/2014

Reformulação 17/06/2015

Aprovado 08/08/2016

Received 10/23/2014

Reformulated 06/17/2015

Approved 08/08/2016

Recibido 23/10/2014

Reformulado 17/06/2015

Aceptado 08/08/2016

Como citar: Silva, C. F. S., \& Dias, C. M. S. B (2016). Violência contra idosos na família: motivações, sentimentos e necessidades do agressor. Psicologia: Ciência e Profissão, 36(3): 637-652. doi:10.1590/1982-3703001462014

How to cite: Silva, C. F. S., \& Dias, C. M. S. B (2016). Violence against the elderly in the family: aggressor's motivations, feelings and needs. Psicologia: Ciência e Profissão, 36(3): 637-652. doi:10.1590/1982-3703001462014

Cómo citar: Silva, C. F. S., \& Dias, C. M. S. B (2016). La violencia contra las personas mayores en la familia: motivaciones, sentimientos y necesidades de los agresores. Psicologia: Ciência e Profissão, 36(3): 637-652. doi:10.1590/1982-3703001462014 